\title{
Standardised removal and sectioning locations for shovelnose sturgeon fin rays
}

\author{
J. D. KOCH, W. J. SCHRECK \& M. C. QUIST \\ Department of Natural Resource Ecology and Management, Iowa State University, Ames, IA, USA
}

\begin{abstract}
Fin rays are a common structure used in age and growth analyses, but many inconsistencies exist regarding removal and processing methodology. The purpose of this study was to evaluate precision of age estimates obtained from shovelnose sturgeon, Scaphirhynchus platorynchus (Rafinesque) fin rays sectioned at different locations. Fin rays were examined from 203 shovelnose sturgeon sampled from Pools 9, 13 and 14 of the Mississippi River. Three readers provided age estimates for sections acquired from five locations along fin rays to determine the optimum location for removing and sectioning fin rays. Precision and readability were generally greater for fin ray sections close to the articulating process on the fin ray (i.e. proximal) and decreased as sections approached the tip (i.e. distal). Based on these results, it is recommended that scientists remove shovelnose sturgeon fin rays at the articulating process and section immediately distal to the conspicuous curve in the fin ray close to the articulating process of the ray.
\end{abstract}

KEYWORDS: ageing, fin ray, shovelnose sturgeon.

\section{Introduction}

Accurate and precise estimation of age is essential in fisheries management. Standardised collection of ageing structures and ageing techniques is necessary to ensure that meaningful and comparable results are obtained for guiding management actions. Several structures are commonly used to estimate age that do not require killing fish, including scales, fin rays and spines (DeVries \& Frie 1996). Scales have traditionally been the most often used structure for age and growth analyses, but the use of fin rays and spines has steadily increased. This increase may be attributed to species anatomy (viz. scales may be absent for some species such as ictalurids and acipenserids) or because scales may not provide reliable age estimates for species that cannot be killed (e.g. endangered, threatened, or sensitive species; Metcalf \& Swearer 2005; Maceina, Boxrucker, Buckmeier, Gangl, Lucchesi, Isermann, Jackson \& Martinez 2007, Quist, Jackson, Bower \& Hubert 2007).

Although research has shown that fin ray removal does not influence survival or growth of fish (e.g. Collins \& Smith 1996), concerns regarding fish injury remain. Concerns associated with removing the entire fin ray (e.g. infection, loss of stability) may lead to improper and inconsistent removal techniques, thus potentially limiting the utility of the structure for age and growth analysis. Also, a lack of consistency of fin ray removal location in the literature suggests a need for standardisation. Often when referring to extraction locations, only vague descriptions are provided, such as 'as close to the base of the fin as possible' (Mills \& Beamish 1980) or 'close to the body' (Quinn \& Ross 1982). Exact measurements can be found in the literature, but most are described with differing points of reference, such as 'sections were obtained 1.0$1.5 \mathrm{~cm}$ above the point where the ray base started to flare' (Beamish 1981) or 'approximately $1.0-\mathrm{cm}$ segment of the ray remained attached to the pectoral girdle' (Parsons, Hoover \& Killgore 2003). Inconsistent sectioning or removal locations of ageing structures may lead to inaccurate age and growth data. For instance, Sneed (1951) obtained longitudinal sections of channel catfish, Ictalurus punctatus (Rafinesque) pectoral spines (i.e. distal to the basal groove) and found that annuli from young ages were not present at the distal portion of the spine. Because of these inconsistencies, an examination of the importance of standardised fin ray removal and sectioning locations 
is warranted. The objective of this study was to examine the precision of age estimates and readability of presumptive annuli obtained from shovelnose sturgeon, Scaphirhynchus platorynchus (Rafinesque) pectoral fin rays sectioned at various distances from the articulation with the pectoral girdle.

\section{Materials and methods}

Shovelnose sturgeon were collected from the upper Mississippi River (Pools 9, 13, and 14) using 30.5-m drifted trammel nets with $50.1-\mathrm{mm}$ inner mesh and 304.8-mm outer mesh. All shovelnose sturgeon were measured to the nearest millimeter (fork length). The marginal pectoral fin ray (i.e. furthest anterior) was removed from the fish by cutting the ray at the articulation point with a sharp knife (Fig. 1). The articulating point was defined as the point where the fin ray articulated with the pectoral girdle. Fin rays were stored in coin envelopes and allowed to air dry. Five shovelnose sturgeon per 1-cm length group were used except for small and large length groups for which fewer fish were available. Cross sections were taken from five locations along each fin ray to reflect different removal techniques (Fig. 2). The first location (i.e. section 1) corresponds to the point where the proximal end of the fin ray curves away from the body toward the distal tip of the ray. Section 1 represents the location where cross-sections would be taken if the ray was removed at the articulating point of the ray with the pectoral girdle. Under the assumption that all annuli are present and identifiable at section 1, annuli observed from this section will be considered the 'true' estimated age of the individual. Unfortunately, the accuracy of age estimations cannot be examined, as fin rays have not been validated for shovelnose sturgeon. The second section, slightly distal to the first, was taken to reflect removal of the fin ray by clipping the
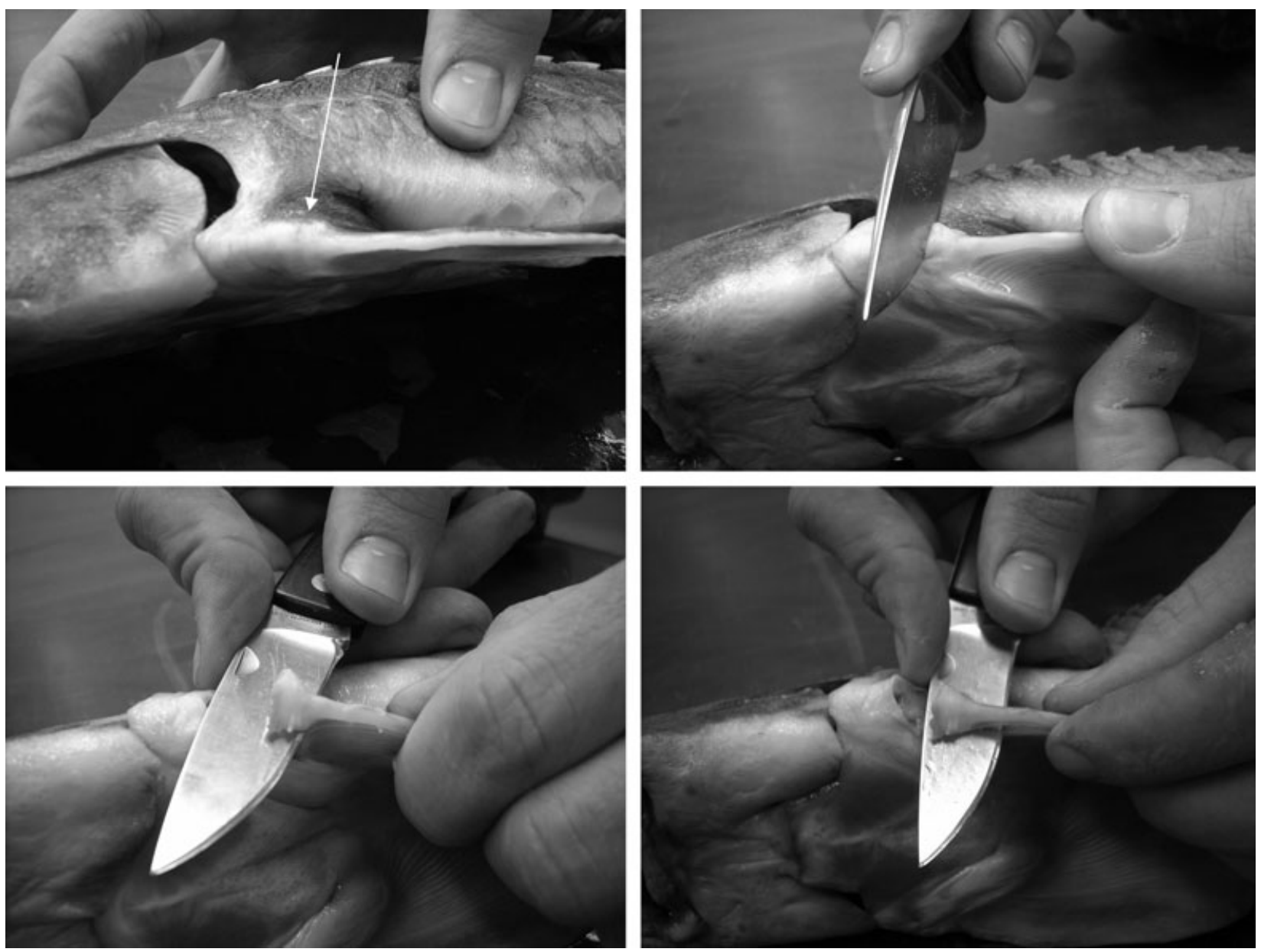

Figure 1. The process of removing shovelnose sturgeon fin rays at the articulation point (white arrow). Note that if care is taken, only the first fin ray is removed with minimal mutilation to the pectoral fin. 


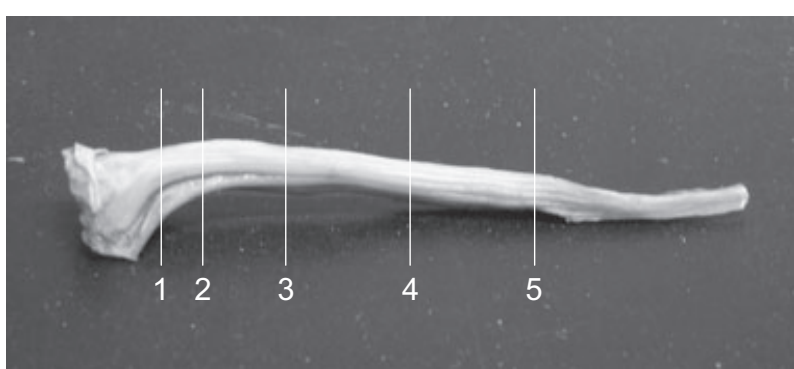

Figure 2. Shovelnose sturgeon marginal pectoral fin ray and approximate locations of five cross sections used to evaluate precision in age estimates.

ray as close to the body as possible with side-cutting pliers. The remaining sections were made at 25,50 and $75 \%$ of fin ray length (i.e. total fin ray length) from the proximal edge of section 1 to the distal tip of the fin ray. For each fin ray, these locations were marked prior to mounting.

Fin rays were mounted in epoxy using the methods described by Koch \& Quist (2007). Longer rays were often mounted in several moulds to ensure that the encapsulated structure remained secure in the saw chuck during sectioning. One $0.50-\mathrm{mm}$ section was cut from each of the five locations using a Buehler Isomet low-speed saw (Buehler, Lake Bluff, IL, USA). Each section was labelled with its corresponding section number and placed in its own coin envelope.

Three readers viewed all sections of each ray and assigned a number of presumptive annuli. Two of the readers had considerable experience in ageing fish (i.e. one with $>10$ year and one with approximately 5 year), and the other reader had $<1$ year experience. Readers independently estimated age and assigned a confidence rating (i.e. readability). Confidence ratings, similar to those used by Fitzgerald, Margenau \& Copes (1997), were integers between 0 and 3 that represented the certainty of an age estimate. A confidence rating of 0 corresponded to no confidence, whereas a rating of 3 represented absolute confidence in the reader's age estimate. Initial age estimates were compared, and when ages disagreed a consensus age (i.e. an age agreed upon by all readers in a mutual examination) was assigned. A consensus age was often not available for sections with poor readability. All sections without a consensus age were removed from subsequent analyses. Each section was aged without knowledge of the fish's length or weight.

Between-reader agreement and individual reader agreement with consensus age was assessed for exact age and age within 1 year. Precision of age estimates was evaluated using the coefficient of variation $(\mathrm{CV}$;
Campana, Annand \& McMillan 1995). Age estimates were also examined by confidence rating to provide insight on the readability of different section locations and the effect of readability on precision. Age-structure distributions were calculated for consensus age estimations from each section and compared using a Kolmogorov-Smirnov test using SAS (SAS Institute 1996). A Bonferroni adjustment for multiple tests was used for all pairwise comparisons of consensus age distributions.

\section{Results}

This study examined 203 shovelnose sturgeon varying in length from 233 to $790 \mathrm{~mm}$. Exact agreement of a reader's initial age estimate with the consensus age differed among readers, but sections 1 and 2 generally had the highest agreement between initial and consensus ages (Table 1). Section 3 generally had the lowest agreement between initial and consensus ages. Most disagreements with consensus age were within 1 year.

Between-reader agreement for initial age estimates was highest for sections 1 and 2, whereas section 3 had the lowest exact agreement (Table 2). Sections 1 and 2 also exhibited the lowest mean CVs. Readers 1 and 2 agreed on $74.5 \%$ of the section 1 and $72.9 \%$ of the section 2 fin ray ages (i.e. initial age estimates), but no two readers had an exact agreement above $50 \%$ on sections 3, 4 or 5. Agreement within 1 year for sections 1 and 2 was above $88 \%$ for all combinations of readers. Sections 3, 4, and 5 had similar within-1-year agreement varying from 73.6 to $79.2 \%$.

Agreement on a consensus age decreased for more distal sections. A consensus age was assigned in over $99 \%$ of the section 1 and $98 \%$ of section 2 fin ray sections. Agreement on a consensus age decreased for sections $3(75 \%$ of the fin ray samples received a consensus age), $4(65 \%)$ and $5(29 \%)$. Consensus age estimates from section 1 concurred with consensus estimates from section 2 only $42.6 \%$ of the time (Fig. 3). Exact agreement of section 1 age estimates with those from sections 3, 4 and 5 were 19.6, 14.5 and $13.8 \%$, respectively. Maximum age for section 1 was 16 years, whereas maximum age for sections $2,3,4$ and 5 were 17, 19, 14 and 12 years, respectively (Fig. 3). Section 2 consensus ages were generally older than section 1 ages for young year classes (ages 1-4), but this relationship was variable after age 5 . Consensus age estimates from section 3 were generally older than consensus ages from section 1 for ages 1-6 and became variable thereafter. In one instance, a section 1 fin ray was aged at 7 years and section 3 was aged at 19 years. Section 4 age estimates also generally were higher than 
Table 1. Precision of initial age estimates for sections along shovelnose sturgeon fin rays (section 1 is proximal, section 5 is distal) expressed as percent exact agreement and percent agreement within 1 year of the consensus age

\begin{tabular}{|c|c|c|c|c|c|}
\hline \multirow[b]{2}{*}{ Reader } & \multicolumn{5}{|c|}{ Section } \\
\hline & 1 & 2 & 3 & 4 & 5 \\
\hline & \multicolumn{5}{|c|}{ Percent exact agreement with consensus age } \\
\hline 1 & $82.1(2.1)$ & $79.9(1.8)$ & $70.8(2.6)$ & $74.8(1.8)$ & $72.9(2.1)$ \\
\hline 2 & $59.7(5.1)$ & $61.8(3.1)$ & $63.0(3.4)$ & $65.7(2.5)$ & $64.4(3.3)$ \\
\hline \multirow[t]{2}{*}{3} & $89.6(1.0)$ & $92.5(0.8)$ & $77.9(2.4)$ & $79.4(1.8)$ & $79.7(2.1)$ \\
\hline & \multicolumn{5}{|c|}{ Percent agreement of consensus age within 1 year } \\
\hline 1 & 96.5 & 95.5 & 91.6 & 96.9 & 89.8 \\
\hline 2 & 89.6 & 90.9 & 87.6 & 93.9 & 89.8 \\
\hline 3 & 97.5 & 98.0 & 91.6 & 93.9 & 95.0 \\
\hline
\end{tabular}

The coefficient of variation $(\mathrm{CV}, \%)$ for percent exact agreement is in parentheses.

Table 2. Precision of age estimates between readers for sections along shovelnose sturgeon fin rays (section 1 is proximal, section 5 is distal) expressed as percent exact agreement and percent agreement within 1 year

\begin{tabular}{|c|c|c|c|c|c|}
\hline \multirow{2}{*}{$\begin{array}{l}\text { Reader } \\
\text { comparison }\end{array}$} & \multicolumn{5}{|c|}{ Section } \\
\hline & 1 & 2 & 3 & 4 & 5 \\
\hline & \multicolumn{5}{|c|}{ Percent exact agreement } \\
\hline 1 vs 2 & $53.7(5.7)$ & $54.2(5.0)$ & $38.3(6.8)$ & $42.3(6.6)$ & $40.3(8.1)$ \\
\hline 1 vs 3 & $74.5(2.4)$ & $72.9(2.8)$ & $42.5(6.5)$ & $44.1(6.6)$ & $48.6(7.1)$ \\
\hline 2 vs 3 & $57.1(5.3)$ & $57.6(4.8)$ & $37.8(6.9)$ & $38.7(7.3)$ & $45.8(6.9)$ \\
\hline & \multicolumn{5}{|c|}{ Percent agreement within 1-year } \\
\hline 1 vs 2 & 86.7 & 88.2 & 77.2 & 79.2 & 73.6 \\
\hline 1 vs 3 & 94.1 & 92.1 & 76.7 & 79.8 & 76.3 \\
\hline 2 vs 3 & 86.2 & 88.7 & 77.2 & 78.6 & 84.6 \\
\hline
\end{tabular}

The coefficient of variation $(\mathrm{CV}, \%)$ for percent exact agreement is shown in parentheses.

section 1 estimates until age 6 , but consistently lower after age 11. In most cases, section 5 ages tended to be lower than section 1 age. The CV was lowest for the comparison of section 1 with section $2(7.8 \%)$, and highest for section 1 with section 5 (17.6\%). Age structure distributions varied depending on which section was examined, but only one pairwise comparison (section 1 vs section 3 ) indicated a significant difference in age distribution $(P=0.0013$; Fig. 4$)$.

All three readers assigned an individual confidence rating of 3 for $21 \%$ of the section 1 samples and $20 \%$ of the section 2 samples. Confidence ratings generally decreased with increasing age estimates, and no section 3,4 , or 5 samples received a maximum confidence rating from all three readers. Exact agreement among all readers was $86 \%$ when all three readers had confidence ratings of 3 for section 1 . The initial age estimate was more likely to agree with the consensus age when the confidence rating was 3 than when confidence ratings were $<3$ (Table 3 ). The within-1year agreement with consensus age was $\geq 98 \%$ for sections 1 and 2 when readers assigned a confidence rating of 3 .

\section{Discussion}

Sectioned fin rays are commonly used for age estimation in a variety of fishes, but the effect of sectioning location along fin rays has not been evaluated. The results of this study demonstrate that the location of a cross-section affects the readability of the section and the resulting age estimate, which in turn affect estimates of dynamic rate functions such as growth and mortality. Although the effect of section location along fin rays has not been evaluated, Sneed (1951) conducted a similar study where channel catfish pectoral spines were sectioned longitudinally (i.e. distal to the basal groove) to locate the region where all annuli were present in a cross-section. The author found that if a cross-section was cut too far toward the tip of the spine, annuli representing the first years of growth were not visible. Consequently, Sneed (1951) recommended that cross-sections for age and growth estimation should be cut near the base or in the articulating process of the spine. Although shovelnose sturgeon fin rays and ictalurid spines are different, albeit similar structures, the results indicate sections 

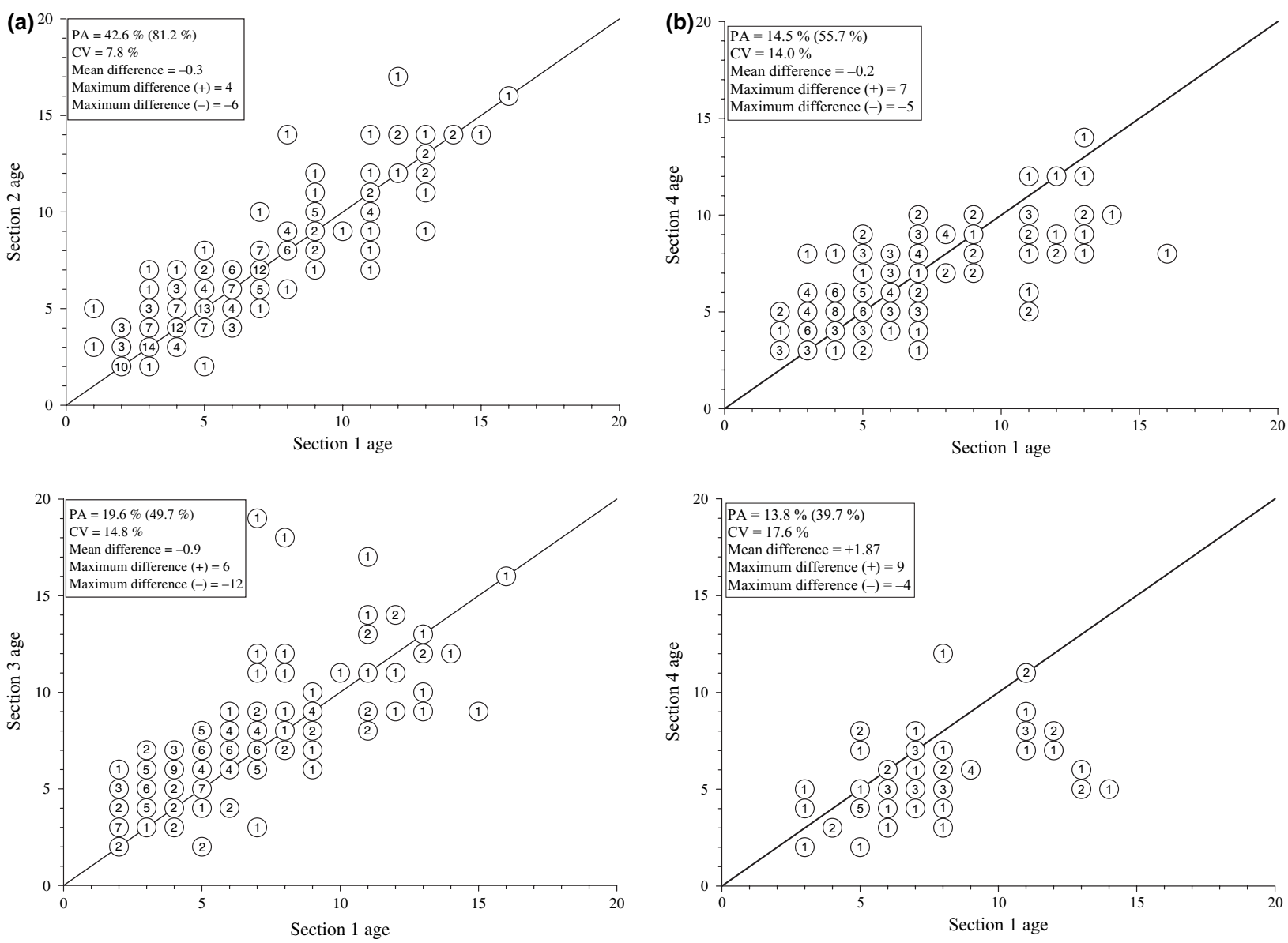

Figure 3. Age-bias plots for consensus ages of sections along a shovelnose sturgeon fin ray (section 1 is proximal, section 5 is distal). Precision between sections was measured as percent exact agreement (PA; value outside parentheses), percent agreement within 1 year (value inside parentheses), and mean coefficient of variation (CV). Numbers in circles are the number of shovelnose sturgeon at each age.

from the proximal end of the spine (i.e. just distal to the conspicuous curve) provided the highest quality section and resulted in the greatest precision among readers and the least deviation from a consensus estimate of the number of annuli. In contrast, many sections taken distal to sections 1 and 2 were not readable or provided age estimates vastly different from sections taken near the articulation point. Moving distally, annuli became less distinct, were usually clustered toward the outer edge of the section, and often formed bands of conjugated annuli.

This study demonstrated that age estimates from shovelnose sturgeon fin rays can be relatively precise when sections close to the articulating process are analysed. This is in contrast to other studies that have obtained imprecise age estimates from shovelnose sturgeon fin rays. For example, Whiteman, Travnichek, Wildhaber, DeLonay, Papoulias \& Tillett (2004) found a between-reader agreement of $18 \%$, while Morrow, Kirk, Killgore \& George (1998) had 32\% agreement for shovelnose sturgeon fin rays. Hurley, Sheehan \& Heidinger (2004) found between-reader agreement was $47 \%$ for pallid sturgeon Scaphirhynchus albus (Forbes \& Richardson) pectoral fin ray sections. One possible reason for these differences is experience of the readers. Section location influenced readability and precision, but the current study also illustrated the importance of experience interpreting fin rays where experienced readers tended to agree more often than a less-experienced reader.

Confidence-ranking systems may also prove beneficial when ageing fishes. Fitzgerald et al. (1997) used a similar confidence-ranking system when ageing the scales of known-age muskellunge, Esox masquinongy Mitchill, but found that confidence ranking had no relation with accuracy of individual age estimates. Although the present assessment of shovelnose sturgeon pectoral rays cannot attest to the accuracy of the ages, the age estimates were more precise at higher levels of reader confidence. 

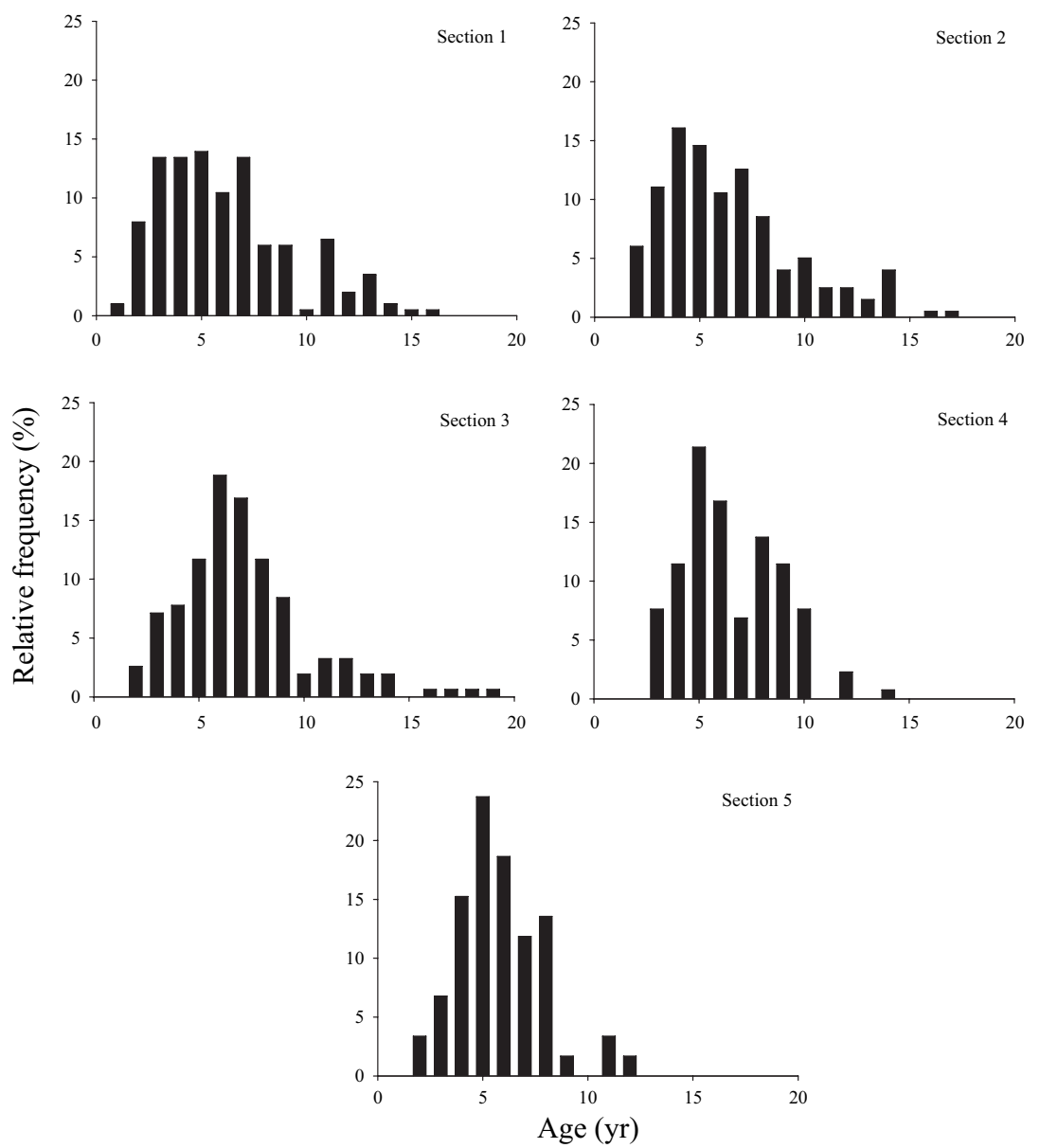

Figure 4. Age frequency distributions of shovelnose sturgeon populations calculated using information from sections obtained from different locations along pectoral fin rays (section 1 is most proximal, section 5 is most distal).

Table 3. Precision of age estimates for sections along shovelnose sturgeon fin rays (section 1 is proximal, section 5 is distal) by confidence rating $(0=$ no confidence, $3=$ absolute confidence $)$

\begin{tabular}{lcccccc}
\hline \multirow{2}{*}{ Rating } & & \multicolumn{5}{c}{ Section } \\
\cline { 2 - 7 } & Reader & 1 & 2 & 3 & 4 & 5 \\
\hline 0 & 1 & $66.7(100) 3$ & $84.6(92.3) 13$ & $69.7(92.5) 66$ & $68.1(94.2) 69$ & $72.9(95.8) 48$ \\
& 2 & $15.4(76.9) 13$ & $76.9(100) 13$ & $61.5(84.6) 52$ & $66.7(91.7) 60$ & $62.5(85.0) 40$ \\
& 3 & $100.0(100) 2$ & $70.0(100) 10$ & $72.6(89.3) 84$ & $73.0(91.0) 89$ & $76.1(93.5) 46$ \\
1 & 1 & $71.4(95.2) 21$ & $47.4(84.2) 19$ & $64.0(92.0) 50$ & $82.6(100) 46$ & $75.0(87.5) 8$ \\
& 2 & $33.3(75.0) 48$ & $38.9(79.6) 54$ & $60.0(86.2) 65$ & $70.6(96.1) 51$ & $72.2(100) 18$ \\
& 3 & $78.6(100) 14$ & $83.3(94.4) 18$ & $75.7(91.1) 37$ & $93.9(100) 33$ & $88.9(100) 9$ \\
2 & 1 & $77.2(93.7) 79$ & $66.7(94.7) 57$ & $76.9(92.3) 26$ & $81.3(100) 16$ & $50.0(100) 2$ \\
& 2 & $62.4(93.0) 85$ & $56.6(92.7) 83$ & $71.4(97.1) 35$ & $50.0(95.0) 20$ & $0.0(100) 1$ \\
& 3 & $63.6(91.0) 44$ & $88.5(96.2) 61$ & $91.3(95.6) 23$ & $88.9(100) 9$ & $100.0(100) 4$ \\
3 & 1 & $88.8(99.0) 98$ & $91.8(98.2) 110$ & $91.7(100) 12$ & N/A & $100.0(100) 1$ \\
& 2 & $89.1(100) 55$ & $91.8(98.0) 49$ & $50.0(50.0) 2$ & N/A & N/A \\
& 3 & $98.6(99.3) 141$ & $98.2(99.1) 110$ & $100.0(100) 10$ & N/A & N/A \\
\hline
\end{tabular}

Precision between sections from same fin ray expressed as percent exact agreement and percent agreement within 1 year (in parentheses) of initial and consensus ages. The bottom number in each cell represents sample size for which a confidence rating was provided by the reader. Not available $(\mathrm{N} / \mathrm{A})$ indicates that a given confidence rating was not provided for any of the sections. 
In light of these results, scientists should remove fin rays from shovelnose sturgeon as close to the articulating point as possible, ensuring that the 'curve' of the fin ray is available for sectioning. In addition, low precision of age estimates obtained from different locations on the same fin ray emphasises the need to standardise sectioning location on fin rays. Although sections 1 and 2 provided precise estimates of age, scientists should remove the fin ray at the articulating process because this allows for the use of a standard sectioning location (i.e. the 'curve' of the fin ray; section 1). This study focuses on shovelnose sturgeon, but similar results might be expected for other fishes. Replication of the study reported herein is encouraged, including assignment of confidence ranks with a sample of known-age shovelnose sturgeon.

\section{Acknowledgments}

We thank Kyle Bartachek, Kirk Hansen, Gene Jones, and Patrick Short for assistance in the field. Comments from three anonymous reviewers greatly improved this manuscript. Zachary Jackson and David Rowe also provided helpful comments on an earlier version of the manuscript. Funding for this project was provided by the Iowa Department of Natural Resources, US Fish and Wildlife Service, and the Department of Natural Resource Ecology and Management at Iowa State University.

\section{References}

Beamish R.J. (1981) Use of fin-ray sections to age walleye pollock, Pacific cod, and albacore, and the importance of this method. Transactions of the American Fisheries Society 110, 287-299.

Campana S.E., Annand M.C. \& McMillan J.I. (1995) Graphical and statistical methods for determining the consistency of age determinations. Transactions of the American Fisheries Society 134, 866-871.

Collins M.R. \& Smith T.I.J. (1996) Sturgeon fin ray removal is nondeleterious. North American Journal of Fisheries Management 16, 939-941.

DeVries D.R. \& Frie R.V. (1996) Determination of age and growth. In: B.R. Murphy \& D.W. Willis (eds) Fisheries Techniques, 2nd edn. Bethesda, MD: American Fisheries Society, pp. 483-512.

Fitzgerald T.J., Margenau T.L. \& Copes F.A. (1997) Muskellunge scale interpretation: the question of aging accuracy. North American Journal of Fisheries Management 17, 206-209.
Hurley K.L., Sheehan R.J. \& Heidinger R.C. (2004) Accuracy and precision of age estimates for pallid sturgeon from pectoral fin rays. North American Journal of Fisheries Management 24, 715-718.

Koch J.D. \& Quist M.C. (2007) A technique for preparing fin rays and spines for age and growth analysis. North American Journal of Fisheries Manangement 27, 782784.

Maceina M.J., Boxrucker J., Buckmeier D.L., Gangl R.S., Lucchesi D.O., Isermann D.A., Jackson J.R. \& Martinez P.J. (2007) Current status and review of freshwater fish aging procedures used by state and provincial fisheries agencies with recommendations for future directions. Fisheries 32, 329-340.

Metcalf S.J. \& Swearer S.E. (2005) Non-destructive ageing in Notolabrus tetricus using dorsal spines with an emphasis on the benefits for protected, endangered, and fished species. Journal of Fish Biology 66, 1740-1747.

Mills K.H. \& Beamish R.J. (1980) Comparison of fin-ray and scale age determinations for lake whitefish (Coregonus clupeaformis) and their implications for estimates of growth and annual survival. Canadian Journal of Fisheries and Aquatic Sciences 37, 534-544.

Morrow J.V. Jr, Kirk J.P., Killgore K.J. \& George S.G. (1998) Age, growth, and mortality of shovelnose sturgeon in the lower Mississippi River. North American Journal of Fisheries Management 18, 725-730.

Parsons G.R., Hoover J.J. \& Killgore K.J. (2003) Effect of pectoral fin ray removal on station-holding ability of shovelnose sturgeon. North American Journal of Fisheries Management 23, 742-747.

Quinn S.P. \& Ross M.R. (1982) Annulus formation by white suckers and the reliability of pectoral fin rays for ageing them. North American Journal of Fisheries Management 2 , 204-208.

Quist M.C., Jackson Z.J., Bower M.R. \& Hubert W.A. (2007) Precision of hard structures used to estimate age of riverine catostomids and cyprinids in the upper Colorado River basin. North American Journal of Fisheries Management 27, 643-649.

SAS Institute (1996) SAS/STAT User's Guide for Personal Computers, Version 6. Cary, NC: SAS Institute. 686 pp.

Sneed K.E. (1951) A method for calculating the growth of channel catfish, Ictalurus lacustris punctatus. Transactions of the American Fisheries Society 80, 174-183.

Whiteman K.W., Travnichek V.H., Wildhaber M.L., DeLonay A., Papoulias D. \& Tillett D. (2004) Age estimation for shovelnose sturgeon: a cautionary note based on annulus formation in pectoral fin rays. North American Journal of Fisheries Management 24, 731-734. 